\title{
A Validation Study of the Korean-Ruminative Response Scale in Korean Adolescents
}

\author{
Kyoung Min Shin ${ }^{1}$, Sun-Mi Cho ${ }^{\bowtie}$, and Keun-Hyang Kim ${ }^{2 凶}$ \\ ${ }^{1}$ Department of Psychiatry \& Behavioral Science, Ajou University School of Medicine, Suwon, Republic of Korea \\ ${ }^{2}$ Department of Psychology, Daegu University, Gyongsan, Republic of Korea
}

Objective We aimed to evaluate the psychometric properties of Korean version of Ruminative Response Scale (K-RRS) for Korean adolescents.

Methods A community sample of 1220 adolescents was recruited from middle schools and high schools. Exploratory factor analyses and confirmatory factor analyses were conducted, and additional analyses were performed to assess the reliability and validity of the K-RRS.

Results An exploratory factor analysis of a sample of adolescents $(n=550)$ yielded a three factor structure: 'depressive rumination', 'reflective pondering', and 'brooding'. Confirmatory factor analyses of another sample of adolescents $(\mathrm{n}=530)$ supported the three-factor model for the K-RRS. The K-RRS was found to have good internal consistency and construct validity.

Conclusion Our results suggest that K-RRS is a valid measurement to assess rumination in adolescents, as well as in adults.

Psychiatry Investig 2015;12(4):508-515

Key Words Ruminative Response Scale, Validation, Adolescence, Factor structure.

\section{INTRODUCTION}

Rumination is a repetitive and conscious thought focusing on the same theme, and it suggests intrusive and unpleasant cognitive processes..$^{1,2}$ Rumination is considered as a relatively stable maladaptive coping strategy that maintains or exacerbates negative emotions. ${ }^{3,4}$ Furthermore, rumination is a symptomatic feature of both dysthymia and depression, and it is regarded as a vulnerability factor and persistence factor of depression. ${ }^{5,6} \mathrm{~A}$ recent study revealed that rumination can substantially contribute to triggering or experiencing anger. ${ }^{7}$

Several measurements have been developed to assess rumination as follows: Ruminative Response Scale (RRS), ${ }^{8}$ Rumina-

Received: December 31, 2013 Revised: October 24, 2014

Accepted: November 10, 2014 Available online: September 30, 2015

$\triangle$ Correspondence: Sun-Mi Cho, $\mathrm{PhD}$

Department of Psychiatry \& Behavioral Science, Ajou University School of Medicine, 164 Worldcup-ro, Yeongtong-gu, Suwon 16499, Republic of Korea Tel: +82-31-219-5180, Fax: +82-31-219-5179, E-mail: smcho@ajou.ac.kr

$\triangle$ Correspondence: Keun-Hyang Kim, PhD

Department of Psychology, Daegu University, 201 Daegudae-ro, Gyeongsan 38453, Republic of Korea

Tel: +82-53-850-6360, Fax: +82-53-850-6369, E-mail: kh.kim@daegu.ac.kr

(c) This is an Open Access article distributed under the terms of the Creative Commons Attribution Non-Commercial License (http://creativecommons.org/licenses/by$\mathrm{nc} / 3.0$ ) which permits unrestricted non-commercial use, distribution, and reproduction in any medium, provided the original work is properly cited. tion on Sadness Scale (RSS), ${ }^{9}$ and Ruminative Thought Style Questionnaire (RTS). ${ }^{10}$ Among these measurements, NolenHoeksema and Morrow ${ }^{8}$ developed the Ruminative Response Scale (RRS) which is a subscale of the Response Style Questionnaire (RSQ). The RRS consists of 22 items describing ruminative responses which are related to depressed mood.

Numerous validity studies of the RRS have shown that a moderate correlation was observed between the RRS scores and depression symptoms, and correlations were found among the RRS scores, current depressive symptoms, worst depressive symptoms in lifetime, neurosis, Beck Depression Inventory, and Mood and Feeling Questionnaire (MFQ). ${ }^{11-13}$ Also Lam et al. ${ }^{14}$ found that the RRS scores predict severity of depression and higher ruminative response style is closely linked with social function impairment in a non-clinical population. Furthermore, several studies have shown that rumination response measured with the RRS predicts severity and duration of depressive episodes in depressed patients. ${ }^{11,15,16}$ Nolen-Hoeksema reported that rumination predicted depressive disorders, including new onsets of depressive episodes and chronicity of depressive disorders. ${ }^{16}$ Robert et al. ${ }^{11}$ suggested that rumination might reflect an important cognitive manifestation of neuroticism that increase vulnerability to episodes of persistent dysphoria. 
The RRS is the most widely used measurement for assessing ruminative response since it is known to have a good validity, including both predictive and concurrent validity.

The factor analyses of the RRS have also been investigated in various samples. Roberts et al. ${ }^{11}$ conducted an exploratory factor analysis on the RRS scores of undergraduates and retained a three-factor model of which the factors were labeled as 'symptom-based rumination', 'introspection and self-isolation', and 'self-blame.' Treynor et al. ${ }^{17}$ attempted to remove 12 depressionrelated items from the RRS and conducted factor analyses in an adult community sample. These analyses indicated a two-factor model of which the factors were labeled as 'reflective pondering' and 'brooding. The items on the reflection factor suggest a purposeful turning inward to engage in cognitive problem solving to alleviate one's depressive symptoms. In contrast, the items on the brooding factor reflect a passive comparison of one's current situation with some unachieved standard. In a Korean population, a three-factor model was identified on the RRS scores of undergraduates as follows: 'selfreproach', 'reflection', and 'depressive rumination. ${ }^{18}$ In addition, Lam et al., ${ }^{14}$ conducted exploratory factor analysis on the RRS scores of depressed outpatients and identified a four-factor model as follows: 'symptom-based rumination', 'isolation/introspection', 'self-blame', and 'analysis to understand.

Rumination has been regarded as one of the processes that transforms normative distress, especially sadness, into depression ${ }^{19}$ and was mentioned as a critical factor to explain depression in adolescents as well as in adults. ${ }^{20}$

Rumination has also been advanced as a possible explanation for both the increase in depressive symptoms as well as the emergence of gender differences in depressive symptoms, during adolescence..$^{21-23}$ However, mixed results have been reported regarding an association between rumination and depression in adolescents, ${ }^{24-27}$ and empirical evidence for rumination during this critical period is still lacking. Furthermore, there is only one validity study to date regarding the RRS in adolescents, which was conducted by Burwell and Shirk. ${ }^{28} \mathrm{~A}$ total of 168 adolescents from a community participated in their study and exploratory factor analyses were performed. They retained a two-factor model of which the factors were labeled 'brooding' and 'reflection', and the items included in each factor were similar to principal components analysis results of Treynor et al. ${ }^{17}$ However, participants were instructed to endorse self-relevant and specific social stressors while completing the RRS which is different from the original method of administration. Thus, some findings from their study may not be generalized to other samples.

In the present study, we examined validity of the RRS which is the most widely used, empirically and theoretically support the measurement for rumination in Korean adoles- cents. In particular, we examined factor structure of the RRS and psychometric properties such as reliability and validity.

\section{METHODS}

\section{Participants}

A community sample of 1220 adolescents was recruited from middle schools and high schools in Seoul (2.7\%), Daejeon (45.7\%), Daegu (9.8\%), and Gyeonggi Province (41.9\%) from January 2012 until June 2012. The purpose and methodology of the present study were reviewed by school authorities, who confirmed that risk of the study was very low. All students received an explanation of the study, and every procedure was conducted under the permission of class teachers. Of the 1220 participants, 1117 (559 boys, 558 girls) signed the consent forms; and 1080 participants provided with complete data, so they were included in the analysis. Participants were randomly assigned to group A or group B. Exploratory factor analyses were conducted in group $A(n=550)$, and confirmatory factor analyses were conducted in group B $(\mathrm{n}=530)$. Of the 1080 participants, 107 were in the first year of middle school, 141 were in the second year of middle school, 146 were in the third year of middle school, 223 were in the first year of high school, 230 were in the second year of high school, and 233 were in the third year of high school, at the time of assessment.

\section{Measurements}

\section{Korean-Ruminative Response Scale}

The Ruminative Response Scale (RRS), which is a part of the larger Response Styles Questionnaire, includes 22 items describing the ruminative responses which are highly related to depressed mood. ${ }^{19}$ The RRS demonstrated high internal reliability, with Cronbach's a ranging from $0.88-0.92 ; ;^{15,19,29-33}$ and good test-retest reliability was shown with the range from $0.67-0.80 .^{30-32}$ Each item is scored on a 4-point Likert scale ranging from 1 (almost never) to 4 (almost always), yielding the total scores ranging from 22 to 88 . A higher score of RRS indicates prominent ruminative response style. The Korean version of Ruminative Response Scale (K-RRS) was used in the study and the Cronbach's $\alpha$ was $0.89 .^{18}$

\section{Children's Depression Inventory}

The Children's Depression Inventory (CDI) is a 27-item selfreport questionnaire designed to assess various symptoms of depression in children and adolescents of age 7-17 years. ${ }^{34}$ Each item consists of three statements from which the child is instructed to choose the one that best describes him or her over the past 1 week. Each item is scored 0, 1, or 2 with a score of 2 representing the most severe choice. The total scores on 
the CDI range from 0 to 54. A higher score of CDI indicates greater depressive symptoms. Although a few participants in this sample (5.37\%) were older than the normative age limit of 17 , the CDI is clinically used in 18-year-olds to maintain consistency of measures with prior researches on adolescents. ${ }^{35,36}$ The Korean version of Children's Depression Inventory was used in the present study and the Cronbach's a was $0.88 .{ }^{37}$

\section{Revised Children's Manifest Anxiety Scale}

The Revised Children's Manifest Anxiety Scale (RCMAS) is a 37 -item self-report instrument designed to assess the traits of anxiety in children and adolescents of age 6-19 years. ${ }^{38}$ The RCMAS consists of 28 Anxiety items and 9 Lie (social desirability) items. A response of "Yes" indicates that the item is descriptive of the subject's feelings or actions, whereas a response of "No" indicates that the item is generally not descriptive. The Korean version of Revised Children's Manifest Anxiety Scale was used in the study. ${ }^{39}$

\section{Statistical analysis}

Exploratory factor analyses were conducted to identify the factor structure of the K-RRS, using SPSS version 20 for Windows. Additional analyses were performed to assess test reliability and validity of the K-RRS. Confirmatory factor analyses were conducted for extracted factors using AMOS Version 20, and the goodness of fit model was evaluated.

\section{RESULTS}

\section{Factor analysis of the Ruminative Response Scale among Korean adolescents}

\section{Exploratory factor analysis}

We conducted exploratory factor analysis of the Ruminative Response Scale among Korean adolescents using principal component analysis with Oblimin rotation, as correlated factors were hypothesized. Exploratory factor analyses results are presented in Table 1. Our analyses resulted in three factors with eigenvalues greater than 1 , which accounted for a total of $58.85 \%$ of the variance. Factor 1 accounted for a total of $48.13 \%$, Factor 2 accounted for a total of $5.89 \%$ and Factor 3 accounted for $4.84 \%$.

Table 1. Exploratory factor analysis of K-RRS among Korean adolescents $(\mathrm{N}=550)$

\begin{tabular}{|c|c|c|c|c|}
\hline & \multirow{2}{*}{ K-RRS item } & \multicolumn{3}{|c|}{ Rotated factor coefficient } \\
\hline & & Factor 1 & Factor 2 & Factor 3 \\
\hline 1 & Think about how alone you feel. & 0.73 & 0.11 & 0.03 \\
\hline 2 & Think "I won't be able to do my job if I don't snap out of this". & 0.47 & 0.17 & -0.21 \\
\hline 3 & Think about your feelings of fatigue and achiness. & 0.69 & -0.06 & -0.16 \\
\hline 5 & Think "What am I doing to deserve this?" & 0.52 & 0.13 & -0.18 \\
\hline 6 & Think about how passive and unmotivated you feel. & 0.56 & 0.10 & -0.17 \\
\hline 8 & Think about how you don't seem to feel anything anymore. & 0.85 & 0.07 & 0.22 \\
\hline 9 & Think "Why can’t I get going?" & 0.47 & 0.26 & -0.17 \\
\hline 17 & Think about how sad you feel. & 0.64 & 0.25 & -0.04 \\
\hline 19 & Think about how you don't feel up to doing anything. & 0.48 & -0.06 & -0.41 \\
\hline 7 & Analyze recent events to try to understand why you are depressed. & 0.24 & 0.56 & -0.08 \\
\hline 11 & Go away by yourself and think about why you feel this way & 0.08 & 0.56 & -0.28 \\
\hline 12 & Write down what you are thinking and analyze it. & 0.08 & 0.70 & 0.13 \\
\hline 20 & Analyze your personality to try to understand why you are depressed. & -0.10 & 0.77 & -0.23 \\
\hline 21 & Go someplace alone to think about your feelings. & 0.12 & 0.71 & -0.07 \\
\hline 22 & Think about how angry you are with yourself. & 0.09 & 0.57 & -0.14 \\
\hline 4 & Think about how hard it is to concentrate. & 0.48 & -0.29 & -0.52 \\
\hline 10 & Think "Why do I always react this way?" & 0.30 & 0.14 & -0.44 \\
\hline 13 & Think about a recent situation, wishing it had gone better. & -0.02 & 0.10 & -0.74 \\
\hline 14 & Think "I won't be able to concentrate if I keep feeling this way." & 0.05 & 0.17 & -0.64 \\
\hline 15 & Think "Why do I have problems other people don't have?" & 0.26 & 0.16 & -0.49 \\
\hline 16 & Think "Why can't I handle things better?” & 0.01 & 0.05 & -0.81 \\
\hline \multirow[t]{4}{*}{18} & Think about all your shortcomings, failings, faults, mistakes. & -0.02 & 0.20 & -0.69 \\
\hline & Eigenvalue & 10.59 & 1.30 & 1.06 \\
\hline & Variance per factor $(\%)$ & 48.13 & 5.89 & 4.84 \\
\hline & Total variance (\%) & & 58.85 & \\
\hline
\end{tabular}

Factor loadings of 0.4 and above are marked in bold. Factor 1: Depressive Rumination, Factor 2: Reflective Pondering, Factor 3: Brooding 
The items suitable for a factor, as proposed by Floyd and Widaman, ${ }^{40}$ were determined as follows: 1) factor loadings are greater than 0.30-0.40, and 2) factor loading difference should be greater than 0.10 when one item loads on more than two factors.

In our study, Factor 1 was labeled as 'depressive rumination' which consists of 8 items including 'Think about how sad you feel', and 'Think about how alone you feel.' Factor 2 was labeled as 'reflective pondering' which consists of 6 items including 'Write down what you are thinking and analyze it', and 'Analyze your personality to try to understand why you are depressed. Factor 3 was labeled as 'brooding' which consists of 6 items including 'Think "Why can't I handle things better?", and 'Think "Why do I have problems other people don't have?".

\section{Confirmatory factor analysis}

Structural equation modeling approach was conducted to verify the goodness-of-fit of a three-factor model of the K-RRS. First, confirmatory factor analysis was conducted for retained three-factor model from exploratory factor analysis. Then the maximum likelihood method was used for estimating parameters of observation-driven model. The three-factor structural model of K-RRS is presented in Table 2 and Figure 1.

Among the goodness-of-fit indices, CMIN/DF $\left(\chi^{2} / d f\right)$ was greater than 3 which did not meet the criterion suggested by Brinker \& Dozois. ${ }^{10}$ However, considering that $\chi^{2}$ test is sensitive to sample size, other goodness-of-fit indices (GFI $=0.874$, $\mathrm{AGFI}=0.845$, TLI=0.897, CFI=0.908, RMSEA=0.076, RMR= 0.031 ) seemed relatively acceptable. ${ }^{30}$ Therefore, a three-factor model for the K-RRS was considered to be appropriate. Also, the standardized regression coefficients of three factors and 22 items of K-RRS ranged from 0.56 to 0.80 , and all the path coefficients were statistically significant at the level of $\mathrm{p}<0.01$.

\section{Reliability}

\section{Internal consistency}

The Cronbach's a was 0.95 for the entire scale of K-RRS. The Cronbach's a for 'depressive rumination', 'reflective pon-

Table 2. Goodness-of-fit Indices for K-RRS model: confirmatory factor analysis $(N=530)$

\begin{tabular}{cccccc}
\hline Goodness-of-fit Indices & $\chi^{2}$ & $\mathrm{df}$ & RMSEA & TLI & CFI \\
\hline K-RRS three factors 20 items & 654.986 & 167 & 0.074 & 0.910 & 0.921 \\
\hline
\end{tabular}

K-RRS: Korean-Ruminative Response Scale, RMSEA: Root Mean Square Error of Approximation, TLI: Tucker-Lewis Index, CFI: Comparative Fit Index

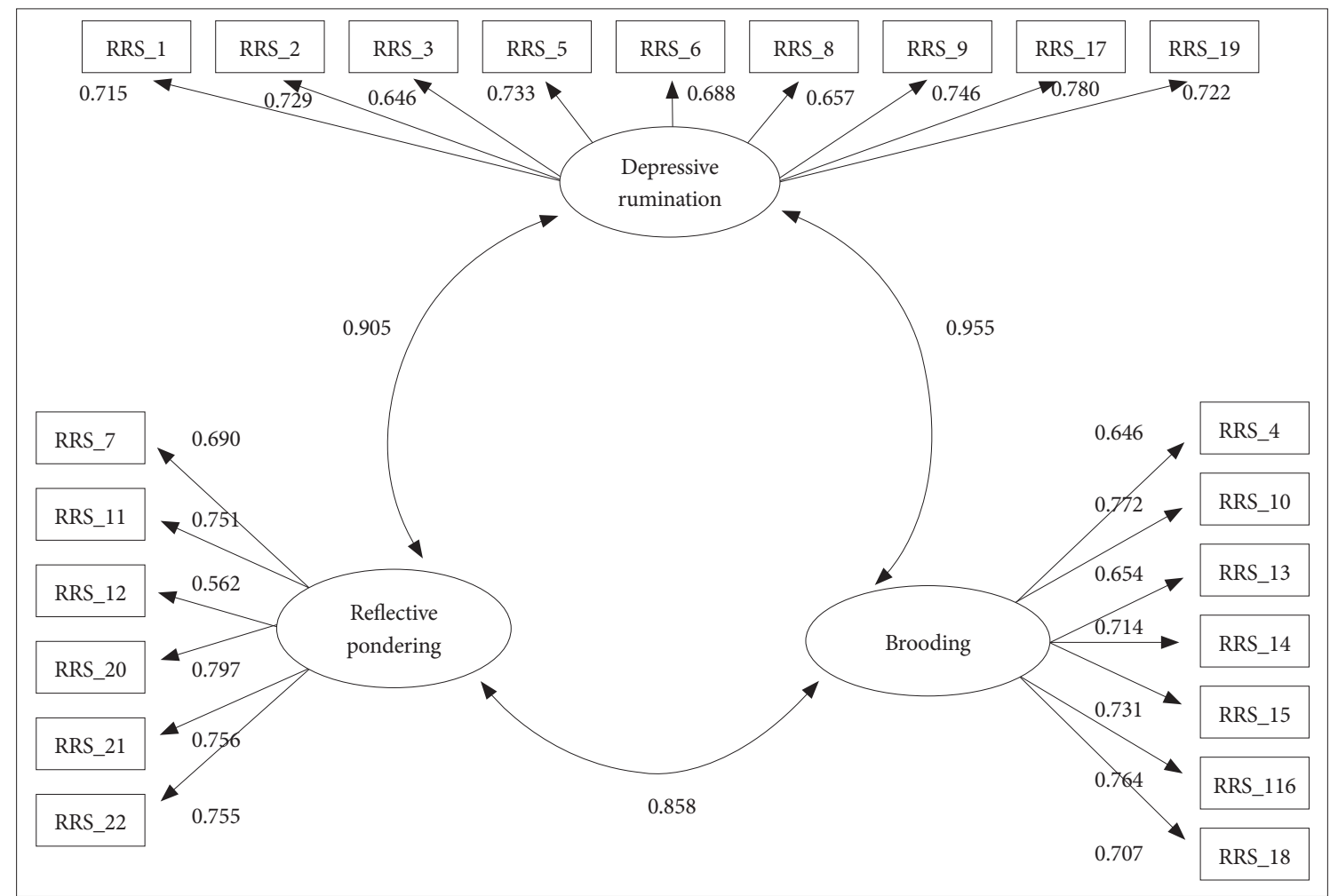

Figure 1. Three-factor structural model of Korean-Ruminative Response Scale (K-RRS). 
dering', and 'brooding' factor were $0.90,0.86$, and 0.88 , respectively. In overall, internal consistency for the sub-factors of K-RRS seemed to be good.

Table 3. Correlation between an item and total score of K-RRS

\begin{tabular}{cc}
\hline K-RRS total score & $\mathrm{p}$ \\
\hline Item 1 & $0.699^{* *}$ \\
Item 2 & $0.722^{* *}$ \\
Item 3 & $0.672^{* *}$ \\
Item 4 & $0.644^{* *}$ \\
Item 5 & $0.720^{* *}$ \\
Item 6 & $0.694^{* *}$ \\
Item 7 & $0.688^{* *}$ \\
Item 8 & $0.627^{* *}$ \\
Item 9 & $0.744^{* *}$ \\
Item 10 & $0.746^{* *}$ \\
Item 11 & $0.733^{* *}$ \\
Item 12 & $0.512^{* *}$ \\
Item 13 & $0.674^{* *}$ \\
Item 14 & $0.722^{* *}$ \\
Item 15 & $0.743^{* *}$ \\
Item 16 & $0.737^{* *}$ \\
Item 17 & $0.775^{* *}$ \\
Item 18 & $0.711^{* *}$ \\
Item 19 & $0.722^{* *}$ \\
Item 20 & $0.717^{* *}$ \\
Item 21 & $0.703^{* *}$ \\
Item 22 & $0.683^{* *}$ \\
\hline -RRS: Koran & 5 ca $^{*}$ \\
\hline
\end{tabular}

\section{Item-total score correlations}

The correlations between an item and the total score of the K-RRS ranged from $\gamma(1108)=0.51$ (item 12) to $\gamma(1108)=0.78$ (item 17) which demonstrates high inter-item consistency (Table 3).

\section{Construct validity}

To explore the relations among K-RRS, CDI, and RCMAS, Pearson's correlations were conducted. As shown in Table 4, significant positive relations were observed among the total score and three sub-factor scores of K-RRS, depression, and trait anxiety indicated good convergent validity.

\section{Gender differences in K-RRS, CDI, and RCMAS}

We examined the gender differences in total score and three sub-factor score of K-RRS, CDI, and RCMAS (presented in Table 5). Girls showed significantly higher scores on KRRS total scores, depressive rumination factor, reflective pondering factor, brooding factor, and RCMAS compared to boys. However, gender differences were not apparent in CDI scores.

\section{DISCUSSION}

In this study we explored factor structure of the RRS, which is designed to measure rumination in Korean adolescents, and we further examined reliability and validity of the RRS.

Our results suggest that Cronbach's $\alpha$ and inter-item consistency of the K-RRS are adequate in Korean adolescents. In

Table 4. Relations among K-RRS, CDI, and RCMAS (N=1043-1092)

\begin{tabular}{|c|c|c|c|c|c|c|}
\hline Measurement & $\begin{array}{l}\text { K-RRS } \\
\text { total score }\end{array}$ & $\begin{array}{l}\text { Depressive } \\
\text { rumination }\end{array}$ & $\begin{array}{l}\text { Reflective } \\
\text { pondering }\end{array}$ & Brooding & CDI & RCMAS \\
\hline K-RRS total score & - & & & & & \\
\hline Depressive rumination & $0.95^{* *}$ & - & & & & \\
\hline Reflective pondering & $0.88^{* *}$ & $0.77^{* *}$ & - & & & \\
\hline Brooding & $0.93^{* *}$ & $0.83^{* *}$ & $0.72^{* *}$ & - & & \\
\hline CDI & $0.54^{* *}$ & $0.59^{* *}$ & $0.41^{* *}$ & $0.48^{* *}$ & - & \\
\hline RCMAS & $0.62^{* *}$ & $0.63^{* *}$ & $0.46^{* *}$ & $0.60^{* *}$ & $0.63^{* *}$ & - \\
\hline \multicolumn{7}{|c|}{$\begin{array}{l}\text { **p<0.01. K-RRS: Korean-Ruminative Response Scale, CDI: Children's Depression Inventory, RCMAS: Revised Children's Manifest Anxiety } \\
\text { Scale }\end{array}$} \\
\hline & \multicolumn{2}{|c|}{ Boys $(\mathrm{N}=540), \mathrm{M}(\mathrm{SD})$} & \multicolumn{2}{|c|}{ Girls $(\mathrm{N}=540), \mathrm{M}(\mathrm{SD})$} & $\mathrm{t}$ & $\mathrm{p}$ \\
\hline K-RRS total score & \multicolumn{2}{|c|}{$36.31(12.99)$} & \multicolumn{2}{|c|}{$40.73(13.85)$} & -5.42 & 0.000 \\
\hline Depressive rumination & \multicolumn{2}{|c|}{$14.41(5.55)$} & \multicolumn{2}{|c|}{$16.25(5.69)$} & -5.43 & 0.000 \\
\hline Reflective pondering & \multicolumn{2}{|c|}{$9.37(3.69)$} & \multicolumn{2}{|c|}{$10.38(4.11)$} & -4.29 & 0.000 \\
\hline Brooding & \multicolumn{2}{|c|}{$12.57(4.83)$} & \multicolumn{2}{|c|}{$14.13(5.19)$} & -5.15 & 0.000 \\
\hline CDI & \multicolumn{2}{|c|}{$13.86(7.42)$} & \multicolumn{2}{|c|}{$14.05(6.94)$} & -0.42 & 0.67 \\
\hline RCMAS & \multicolumn{2}{|c|}{$9.84(6.02)$} & \multicolumn{2}{|c|}{$12.54(5.66)$} & -7.62 & 0.000 \\
\hline
\end{tabular}

K-RRS: Korean-Ruminative Response Scale, CDI: Children's Depression Inventory, RCMAS: Revised Children's Manifest Anxiety Scale 
addition, internal consistency for the sub-factors of K-RRS was considered to be adequate, which also means that the overall reliability is good. Therefore, it is expected that the sub-factors of the K-RRS would be useful as sub-concepts of rumination in future studies. Furthermore, total score and three sub-factor score of the K-RRS were significantly positively correlated with depression and anxiety which reflects good internal validity. In summary, our results suggest that $\mathrm{K}$-RRS is a useful measurement to assess rumination in adolescents, as well as in adults.

Our exploratory factor analyses resulted in a three-factor model of which the factors were labeled as 'depressive rumination', 'reflective pondering', and 'brooding. This is similar to Roberts and colleagues' analysis which retained a threefactor model, with the factors labeled as 'symptom-based rumination', 'introspection and self-isolation', and 'self-blame. ${ }^{11}$ Also, our factor structure was similar to the adult sample by Treynor et al., ${ }^{17}$ and the sample of Korean college students by Kim et al. ${ }^{18}$ of.

The results of our study with Korean adolescents are consistent with much of the prior researches but we also pointed to some of the important differences from rumination studies of adult samples. First, item 4 (Think about how hard it is to concentrate.) and item 19 (Think about how you don't feel up to doing anything.) were excluded in the present study, whereas, they were included in the studies of adults. Considering that item 4 and 19 were excluded in Burwell \& Shirk' results on adolescents, ${ }^{28}$ questions about concentration or motivation might not be effective for measuring rumination in adolescents because they are under academic pressure and cognitive burden, compared to adults.

Second, gender differences were not observed in CDI which measures depression in children and adolescents; however, girls showed higher scores on total scores and sub-factor scores of the K-RRS. It is regarded as one of the most reliable findings of psychiatric epidemiology that compared to men, women are twice as likely to develop depression, and their depression is likely to be more severe. These gender differences in depression rate do not appear significantly in prepubescent children. However, consensus has been reached that gender differences in depression becomes significant between the ages of 11 and $15 .{ }^{41-43}$ Nolen-Hoeksema demonstrated that gender differences in rumination contribute to the emergence of gender differences in depression during adolescence; that is, girls enter adolescence with a greater tendency to respond to stress with rumination than boys, and this response style contributes to the emergent gender difference in depressive symptoms. ${ }^{20,31}$ In the present study, gender differences were apparent in rumination which is known to have negative effects on depressive symptoms, but gender differences were not observed in depression levels. These results indicate that gender difference may appear in rumination distinctively from current depressive symptoms, which is inconsistent with Nolen-Hoeksema's assertion. Recent studies on rumination have shown similar results as ours, ${ }^{18,26}$ and a few longitudinal studies suggest that rumination is likely to be linked with emergence of future depressive symptoms rather than current depressive symptoms. ${ }^{27,28}$

Lastly, stronger correlations were observed between KRRS and RCMAS, which is an anxiety measurement, than with CDI, which is a depression measurement, and girls showed significantly higher anxiety level than boys in the present study. Recently several researchers argue that rumination is closely linked to depression. However, when anxiety or worrying is considered together, there is less ability to predict depression..$^{44,45}$ Furthermore, a study by Ward et al. ${ }^{46}$ revealed that ruminators tend to feel more insecure about their solutions for a problem, than non-ruminators. Also, Lyubomirskys et al. ${ }^{47}$ reported that the contents of ruminations reflect feelings of insecurity in the controlling or managing situations. This feeling of insecurity is regarded as a main element of anxiety. ${ }^{48,49}$ Nolen-Hoeksema ${ }^{16}$ showed rumination predicted anxiety symptoms as well as depressive disorder, and Brozovich et al. ${ }^{50}$ suggested that rumination may have a more significant role than reappraisal, in understanding the fluctuations of social anxiety during cognitive behavioral therapy for social anxiety disorder. Considering that anxiety is considered as a risk factor for depression as well as rumination, ${ }^{51,52}$ there may be conceptual overlapping between rumination and anxiety, although further research is needed.

The results of our study should be considered in light of the following limitations: 1) structured interview or psychiatric history taking was not performed in the process of recruiting participants. Thus, there is a concern that we may not have distinguished between the normal controls and the participants with mental illness. 2) We were unable to confirm the criterion validity in a clinical sample. It is essential to have normative data when using the K-RRS in the clinical setting. Therefore, further research is needed on the K-RRS of adolescents with anxiety disorders or mood disorders.

In summary, we explored reliability and validity of the RRS which is the most widely used rumination measurement in Korean adolescents, and we also confirmed the sub-factors of rumination by using factor analysis. Our results revealed that $\mathrm{K}-\mathrm{RRS}$ is a valid measurement to assess rumination in adolescents as well as in adults.

\section{REFERENCES}

1. Carson CL, Cupach WR. Fueling the flames of the green-eyed monster: the role of ruminative thought in reaction to romantic jealousy. 
Western J Comm 2000;64:308-330.

2. Sukhodolsky DG, Golub A, Cromwell EN. Development and validation of the anger rumination scale. Pers Individ Dif 2001;31:689-700.

3. Broderick PC, Korteland C. Coping styles and depression in early adolescence: relationships to gender, gender role, and implicit beliefs. Sex Role 2002;46:201-213.

4. Miller N, Pedersen WC, Earleywine M, Pollock VE. Artificial a theoretical model of triggered displace aggression. Pers Soc Psychol Rev 2003;7:57-97.

5. Papageorgiou C, Wells A. Depressive Rumination Nature, Theory and Treatment. Chichester: John Wiley \& Sons; 2004.

6. Kelly O, Matheson K, Ravindran A, Merali Z, Anisman H. Rumination coping among patients with dysthymia before and after pharmachotherapy. Depress Anxiety 2007;24:233-243.

7. Bushman BJ, Bonacci AM, Pedersen WC, Vasquez EA, Miller N. Chewing on it can chew you up: effects of rumination on triggered displaced aggression. J Pers Soc Psychol 2005;88:969-983.

8. Nolen-Hoeksema S, Morrow J. A prospective study of depression and posttraumatic stress symptoms after a natural disaster: the 1989 Loma Prieta Earthquake. J Pers Soc Psychol 1991;61:115-121.

9. Conway M, Csank PAR, Holm SL, Blake CK. On assessing individual differences in rumination on sadness. J Pers Assess 2000;75:404-425.

10. Brinker JK, Dozois DJ. Ruminative thought style and depressed mood. J Clin Psychol 2009;65:1-19.

11. Roberts JE, Gilboa E, Gotlib IH. Ruminative response style and vulnerability to episodes of dysphoria: gender, neuroticism, and episode duration. Cognit Ther Res 1998;22:401-423.

12. Wilkinson PO, Goodyer IM. The effects of cognitive-behavioural therapy on mood-related ruminative response style in depressed adolescents. Child Adolesc Psychiatry Ment Health 2008;2:3.

13. Watkins E, Scott J, Wingrove J, Rimes K, Bathurst N, Steiner H, et al. Rumination-focused cognitive behavior therapy for residual depression: a case series. Behav Res Ther 2007;45:2144-2154.

14. Lam D, Smith N, Checkley S, Rijsdijk F, Sham P. Effect of neuroticism, response style and information processing on depression severity in a clinically depressed sample. Psychol Med 2003;33:469-479.

15. Nolan SA, Roberts JE, Gotlib IH. Neuroticism and ruminative response style as predictors of change in depressive symptomatology. Cognit Ther Res 1998;22:445-455.

16. Nolen-Hoeksema S. The role of rumination in depressive disorders and mixed anxiety/depressive symptoms. J Abnorm Psychol 2000;109:504511.

17. Treynor W, Gonzalez R, Nolen-Hoeksema S. Rumination reconsidered: a psychometric analysis. Cognit Ther Res 2003;27:247-259.

18. Kim SJ, Kim JH, Youn SC. Validation of the Korean-Ruminative Response Scale (K-RRS). Korean J Clin Psychol 2010;29:1-19.

19. Nolen-Heksema S. Responses to depression and their effects on the duration of depressive episodes. J Abnorm Psychol 1991;100:569-582.

20. Nolen-Hoeksema S, Girgus JS. The emergence of gender differences in depression during adolescence. Psychol Bull 1994;115:424-443.

21. Ge X, Lorenz FO, Conger RD, Elder GH, Simons RL. Trajectories of stressful life events and depressive symptoms during adolescence. Dev Psychol 1994;30:467-483.

22. Hankin BL, Abramson LY. Measuring cognitive vulnerability to depression in adolescence: reliability, validity, and gender differences. J Clin Child Adolesc Psychol 2002;31:491-504.

23. Hankin BL, Abramson LY, Moffitt TE, Silva PA, McGee R, Angell KE. Development of depression from preadolescence to young adulthood: emerging sex differences in a 10-year longitudinal study. J Abnorm Psychol 1998;107:128-140.

24. Abela JR, Vanderbilt E, Rochon A. A test of the integration of the response styles and social support theories of depression in third and seventh grade children. J Soc Clin Psychol 2004;23:653-674.

25. Hart BI, Thompson JM. Gender role characteristics and depressive symptomatology among adolescents. J Early Adolesc 1996;16:407-426.
26. Grant KE, Compas BE. Stress and anxious-depressed symptoms among adolescents: searching for mechanisms of risk. J Consult Clin Psychol 1995;63:1015-1021.

27. Schwartz JAJ, Koenig LJ. Response styles and negative affect among adolescents. Cogn Ther Res 1996;20:13-36.

28. Burwell RA, Shirk SR. Subtypes of rumination in adolescence: associations between brooding, reflection, depressive symptoms, and coping. J Clin Child Adolesc Psychol 2007;36:56-65.

29. Bagby RM, Parker JD. Relation of rumination and distraction with neuroticism and extraversion in a sample of patients with major depression. Cogn Ther Res 2001;25:91-102.

30. Nolen-Hoeksema S, Davis CG. "Thanks for sharing that": ruminators and their social support networks. J Pers Soc Psychol 1999;77:801-814.

31. Nolen-Hoeksema S, Larson J, Grayson C. Explaining the gender difference in depressive symptoms. J Pers Soc Psychol 1999;77:1061-1072.

32. Nolen-Hoeksema S, Parker LE, Larson J. Ruminative coping with depressed mood following loss. J Pers Soc Psychol 1994;67:92-104.

33. Just N, Alloy L. The response styles theory of depression: tests and extension of the theory. J Abnorm Psychol 1997;106:221-229.

34. Kovacs M. The children's depression inventory. Psychopharmacol Bull 1958;21:955-988.

35. Kashikar-Zuck S, Allen RR, Noll RB, Graham TB, Ho I, Swain N. Anxiety and depressive symptoms in adolescents with fibromyalgia and their mothers. J Pain 2005;6:31.

36. Logan DE, Claar RL, Scharff L. Social desirability response bias and self-report of psychological distress in pediatric chronic pain patients. Pain 2008;136:366-372.

37. Cho SC, Lee YS. Development of the Korean form of the Kovacs' Children's Depression Inventory. J Korean Neuropsychiatr Assoc 1990; 29:943-955.

38. Reynolds CR, Richmond BO. Factor structure and construct validity of "what I think and feel": the Revised Children's Manifest Anxiety Scale. J Pers Assess 1979;43:281-283.

39. Choi JS, Cho SC. Assessment of anxiety in children: reliability and validity of Revised Children's Manifest Anxiety Scale. J Korean Neuropsychiatr Assoc 1990;29:691-701.

40. Floyd FJ, Widaman KF. Factor analysis in the development and refinement of clinical assessment instruments. Psychol Assess 1995;7:286299.

41. Nolen-Hoeksema S, Girgus IS. The emergence of gender differences in depression during adolescence. Psychol Bull 1994;115:424-443.

42. Weissman MM, Klerman GL. Sex differences in the epidemiology of depression. Arch Gen Psychiatry 1977;34:98-111.

43. Brooks-Gunn J, Petersen AC. Studying the emergence of depression and depressive symptoms during adolescence. J Youth Adolesc 1991; 20:115-119.

44. Muris P, Roelofs J, Meesters C, Boomsma P. Rumination and worry in nonclinical adolescents. Cogn Ther Res 2004;28:539-554.

45. Fresco DM, Frankel AN, Mennin DS, Turk CL, Heimberg RG. Distinct and overlapping features of rumination and worry: the relationship of cognitive production to negative affective states. Cogn Ther Res 2002;26:179-188.

46. Ward A, Lyubomirsky S, Sousa L, Nolen-Hoeksema S. Can’t quite commit: ruminators and uncertainty. Unpublished Manuscript, Swarthmore college; 1999.

47. Lyubomirsky S, Tucker K, Caldwell ND, Berg K. Why ruminators are poor problem solvers: clues from the phenomenology of dysphoric rumination. J Pers Soc Psychol 1999;77:1041-1060.

48. Barlow DH. Anxiety and Its Disorders: The Nature and Treatment of Anxiety and Panic. New York: Guilford Press; 1988

49. Beck AT, Emery G. Anxiety Disorders and Phobias: a cognitive perspective. New York: Basic Books; 1985.

50. Brozovich FA, Goldin P, Lee I, Jazaiery H, Heimberg RG, Gross JJ. The effect of rumination and reappraisal on social anxiety symptoms during cognitive-behavioral therapy for social anxiety disorder. J Clin Psy- 
chol 2015;71:208-218.

51. Lewinsohn PM, Zinbarg R, Seeley JR, Lewinsohn M, Sack WH. Lifetime comorbidity among anxiety disorders and between anxiety disorders and other mental disorders in adolescents. J Anxiety Disord 1997;
11:377-394

52. Wittchen HU, Beesdo K, Bittner A, Goodwin RD. Depressive episodes-evidence for causal role of primary anxiety disorders? Eur Psychiatry 2003;18:384-393. 